\title{
ACIDOSIS WITH AUTO-INTOXICATION IN INFANTS
}

AND CHILDREN

A STUDY OF ONE HUNDRED CONSECUTIVE CASES IN APPARENT

EPIDEMIC FORM *

CARLETON R. METCALF, M.D.

Attending Physician, St. Paul's School; Assistant Visiting Surgeon, Margaret Pillsbury General Hospital.

CONCORD, N. H.

Between Nov. 18, 1913, and Feb. 1, 1914, in Concord, N. H., and its immediate neighborhood, there were approximately two hundred cases of illness associated with the presence of acetone bodies in the urine. They were diagnosed as cases of acidosis, and while some were doubtless of an inconsequential type that would ordinarily have escaped detection, the majority showed definite symptoms of severe autointoxication - symptoms wholly out of proportion to any obvious organic cause. Sporadic cases of acidosis in children, with autointoxication and recurrent vomiting, are not rare in that city; but it appeared that in this instance we had to deal with the disease in epjdemic form. There were nine fatalities.

I have tabulated 102 consecutive cases, two of which were in women, aged, respectively, 38 and 36 . If we eliminate these women we are left with an even hundred cases in infants and children. In the two adults the histories and symptoms were quite analogous to those portrayed in the larger group.

But three infants out of a hundred were less than a year old. Eight were between 1 and 2 years. The great bulk of the patients - eighty in all - were fairly evenly distributed among the ages from 2 to 8 . Then came a few scattering cases up to 13 , the age of the oldest child. There were 59 boys and 41 girls - a deviation from the accepted ratio.

In view of the fact that Concord is a well-to-do city with comfortable homes, one would expect that the majority of the afflicted children would be well nurtured. Twenty of the homes I have listed as fair, the remainder as good or excellent. None were distinctly poor. Either tenements were notably exempt or else their quota escaped detection.

The earliest cases were discovered at Penacook, five miles from Concord, the middle of November. On December 1 a case was reported

* Received for publication Nov. 27, 1914.

* Read before the Annual Joint Meeting of the New England Pediatric Society, the Philadelphia Pediatric Society, and the Pediatric Section of the New York Academy of Medicine at the Academy of Medicine, New York, Nov. 5, 1914. 
at Boscawen, 10 miles distant, and later in the month children were taken ill at Canterbury, 10 miles away in another direction. The first case to be diagnosed in Concord itself occurred on December 1. The fact that a wide territory was involved has a distinct bearing on water and milk as causative factors, for both of these were procured from a variety of sources. In Concord, the city water analyzed exceptionally well; milk came from at least a dozen dealers. In the surrounding towns both milk and water came, as a rule, from the farms on which the patients lived. Two infants were on breast-milk with crackers, added; one had had nothing but breast-milk for three weeks preceding onset - a point at variance with Schrack's opinion (see Morse ${ }^{1}$ ) that the acetone bodies are not excreted with a pure milk diet. There is evidence that no frozen milk had been used and that no unusual food, such as ensilage, had been given to the cattle.

A few children had eaten unwisely just before the onset of symptoms. One child of 6 , for example, went to a party the day before her symptoms began. One of 3 was taken ill four days after eating a large Thanksgiving dinner. One of 5 ate canned shrimp the day before his illness began. One of 3 had pork pie two days before, while in a girl of 5 the parents attributed the attack to mince pie. These indiscretions lose their significance, however, when we find that in nine-tenths of the cases there had been no modification of diet previous to onset.

In only two instances was there evidence of abnormal fat consumption; while, on the contrary, several children'were affected who, in order to prevent acidosis, had been most carefully fed on a carbohydrate diet. Thus a boy of 3 was taken ill who, for five days, had eaten only bread, gruels, toast, potato and milk. A boy of 7 for a week had had no solid food and no fats - simply gruels, broths and milk. A girl of 3 , on account of a preceding tonsillitis, had been on a liquid diet with low fats and low proteids.

It seems probable that we cannot attribute so extensive an epidemic, if one may use the term, to the milk- or water-supplies, to starvation, to undue fat intake, or to any other dietary error.

The statement that a neurotic temperament plays a prominent part in the etiology of acidosis received scant stubstantiation. Not more than a fourth of the children were neurotic. In twenty-one the presence of adenoids was noted. Six children had both adenoids and enlarged tonsils, a point worthy of mention because we have found that the removal of adenoids and tonsils, in the intermittent type of acidosis, may be coincident with recovery.

In three instances the illness was ushered in by a bronchial asthma, beginning about twelve hours before the symptoms of intoxication.

1. Morse: Arch. Pediat., 1905, xxii, 561. 
Four children had follicular tonsillitis immediately preceding. Two had pneumonia, but both pneumonias came late - aftermaths as it were; and in several cases complicated with otitis media the same sequence was observed. Sixty-four children had either a coryza, a bronchitis or both. Occasionally, these two infections were concurrent with the acidosis; more often the infections preceded by three, four, five days or even a week. All told, then, in about 70 per cent. of these cases there was a well-defined infection of the respiratory tract or of its adjacent cavities. If we except one acute nephritis developing ten days after onset, no other types of infection were noted - no instances of complicating appendicitis, for example. In the remaining 30 per cent. - and this group includes two fatal cases - I can put my finger on no suggestive etiologic point.

Many of our patients were too young to attend school; some had apparently come in contact with no other children before they were taken ill. On various occasions two or more children in one house were sick at the same time; but, on the other hand, children were exempted who had been in intimate contact with affected children.

The epidemic was one of first attacks; eighty-four patients were ill of acidosis for the first time. Eleven cases were recurrent. One child had had as many as twenty attacks in eight years. We found that these recurrent attacks were more easily relieved than initial ones, as though a child, in time, acquired a low-grade immunity.

Almost invariably - eighty-six times - the onset was sudden. Prodromal symptoms were the symptoms of a preceding cold or coryza or none at all. Such premonitory derangements as anorexia, listlessness, headache and dizziness were unusual. Three times diarrhea preceded vomiting. Four times the two came together; but as a rule, vomiting came first and was the symptom denoting that a child was ill.

The commoner signs and symptoms enumerated in the text-books, with the number of cases out of a hundred in which they were observed, may well be tabulated:

Signs and Symptoms No. Cases

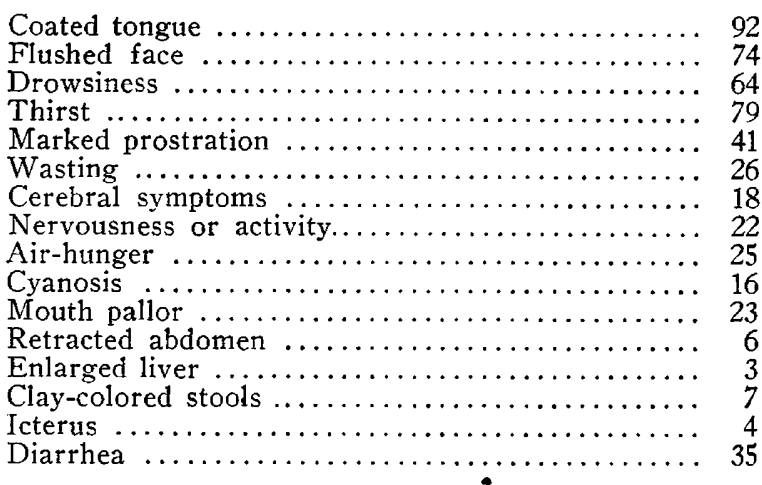


The disease was seen in all degrees of severity. Mild cases yielded very quickly to treatment. Severe cases were pernicious in their activity. Fatal cases were malignant. The average duration of the fatal cases was thirty-two hours, the two extremes being sixteen hours in a baby 14 months old and sixty hours in a child of 5 years.

The more severe the attack the greater was the prostration and wasting, the more evident the meningeal symptoms. So great was the loss of fat in fatal cases that children, in a relatively few hours, shriveled from plumpness to emaciation. With sunken eyes, hollow cheeks and tight-drawn skin they looked not unlike patients in the late stages of phthisis. In such crises delirium and convulsions were expected; twice the clinical picture suggested meningitis.

A coated tongue, a flushed face, drowsiness and thirst were frequent during the active stage of illness. The type of air-hunger peculiar to the disease occurred without cyanosis, but cyanosis did not occur without air-hunger. Rarely a child's face showed complete pallor. Mouth pallor did not occur unless the face was flushed, but, on the other hand, many flushed faces showed no mouth pallor. Retraction of the abdomen was observed only in the more severe and protracted cases, no more frequently, as Griffith ${ }^{2}$ says, than would occur in any asthenic state with empty intestines. Abdominal pain was infrequent, as was enlargement of the liver. Icterus, with clay-colored stools, was not nearly so common as other accounts would lead one to anticipate. One child exhibited a punctate red rash on the second day of disease. Otherwise skin lesions and pruritus (noted by $\mathrm{Marcy}^{3}$ ) were lacking.

In few more than a third of these cases was diarrhea observed. Here we had, characteristically, frequent, watery movements, barely colored, containing mucus and occasional fecal particles. A few stools were dark green, two or three were dark chocolate. Blood was almost never present. Normal or constipated stools, which prevailed in twothirds of the cases, were brown, yellow or black. Watery stools had little odor: those that were solid or semi-solid were usually foul, and in all but one case in which the reaction was tested it was strongly acid. I cannot verify the statement that such stools show an excess of indican (Howland and Richards ${ }^{4}$ ).

In seven cases vomiting was absent. Normally, it was a predominant feature; food first, changing quickly to watery, mucous fluid, either colorless or yellow, like thin pea-soup. Vomiting was propul-

2. Griffith: Am. Jour. Med. Sc., 1900, cxx, 553.

3. Marcy: Internat. Clin., 1900, iii, 127.

4. Howland and Richards: Arch. Pediat., 1907, xxiv, 401. 
sive, frequent and copious. Blood was never present in the vomitus, but in eight instances there were considerable amounts of bile.

Temperature charts showed wide variations. Sixtymfive patients exceeded $100 \mathrm{~F}$., and temperatures of 103 or 104 were not uncommon; 105 was reached but once. Generally speaking, high temperatures were observed when there was delirium and marked prostration. On the other hand, of the fatal cases three ranged about 101, one about 100 and one about 99.4. Even subnormal temperatures were not unheard-of. The pulse was invariably elevated, averaging, with a low temperature, from 100 to 120 . In children with high temperatures the rate ran as high as 160 . There was no evidence of irregularity in the pulse-which heretofore has been described as a common symptom.

Another favorite phrase in the literature is "scanty turbid urine of high specific gravity." In this series we found:

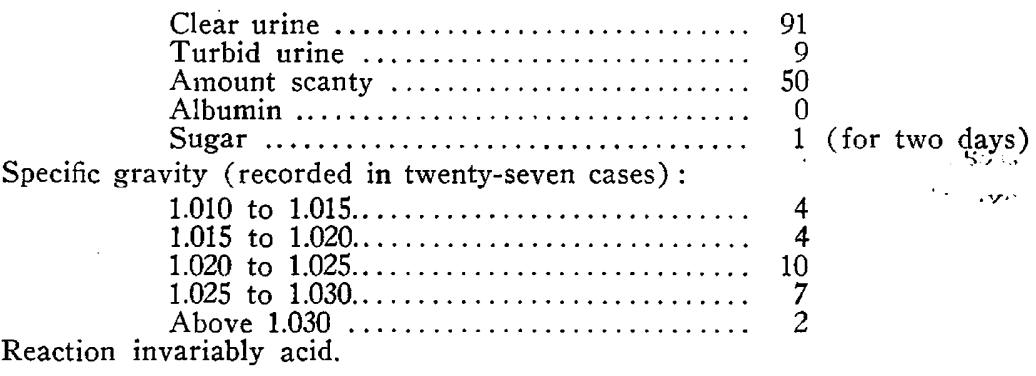

Considerable amounts of acetone were present in the urine in every case. Although exceptionally acetone did not appear in the urine until several hours after onset, in ninety-two cases it was found at the first test - practically at the beginning of acute symptoms - which leads to the belief that acidosis of this type is not a sequel of the persistent vomiting and starvation. Acetonuria almost never ceased while a urine was still acid; it tended, rather, to persist for several days after a urine became alkaline, especially if the diet was scanty, but in such an event a patient showed no toxic symptoms. During this period, however, if the urine was allowed to revert into its former acid condition, toxic symptoms were apt to recur. Acetonuria was of little moment, then, if one could procure alkalinity of the urine.

In examining for acetone, we used, commonly, the somewhat inaccurate nitroprussid test. The Lieben method seemed more delicate, while Rothera's test ${ }^{5}$ is said to act in a dilution of 1 to 130,000 ( Piper $^{6}$ ). Folin ${ }^{\overline{7}}$ has stated that a large amount of acetone can be present in urine without giving a reaction (Piper ${ }^{6}$ ). A fruity odor in the breath, attributed to acetone, was noticed in a fourth of the cases. In several

6. Piper: Lancet, London, 1913, ii, 535.

5. Rothera: Australian Med. Jour., October, 1910.

7. Folin: Jour. Am. Med. Assn., 1907, xlix, 128. 
analyses acetone was isolated in the stools and vomitus but only in minute traces.

In only forty-five individuals was the test for diacetic acid made. Fifteen of these were positive with ferric chlorid, but I believe that others would have yielded a positive reaction had specimens been tested more frequently and immediately after they were passed. We found:

Two fatal cases negative.

Three fatal cases positive.

Nine severe cases positive.

Three moderately severe cases positive.

The appearance of diacetic acid presumably indicated failing powers of oxidation. In an acid urine diacetic acid was a danger signal, and as recovery progressed it disappeared from the urine before acetone did.

Oxybutyric acid was found but once. A single analysis for nitrogen and ammonia gave: nitrogen, $10 \mathrm{gm}$.; ammonia, $0.33 \mathrm{gm}$. -quantities not far from normal. This child had, however, been under alkaline tratment, which would tend to decrease the absolute and relative encretion of ammonia $\left(\right.$ Beddard $\left.^{8}\right)$.

We are told in the literature that recovery from acidosis with autointoxication is very rapid - as rapid as is the onset. This proved true in sixty cases. If we add our nine deaths we still have an appreciable number of patients that recovered slowly, requiring several days. One child died during this convalescence, apparently from exhatustion.

In this series, treatment comprised the administration of aikalies by mouth or by rectum, catharsis, rectal irrigations and the regulation of diet. Eighty-nine children were given sodium bicarbonate by mouth. Eighty successfully retained it. Three could not retain it; three retained it in part; three refused the solution. Soda was retained well in all but one of the fatal cases, although persistence of vomiting was expected until several doses had been given. The stomach proved tolerant of large amounts of soda.

Certain children preferred the dry salt; they deposited a teaspoonful on the tongue and washed it down with a swallow of water. Nevertheless, concentrated solutions tended to irritate the stomach and cause a recurrence of vomiting; and by concentrated solution I mean one stronger than $1: 20:$ a dram of soda to $2 \frac{1}{2} 2$ ounces of water. This ratio and the ratios $1: 32$ and 1:60 never caused nausea. Children who received a dram of the salt each hour or two acquired an alkaline urine in from twenty-four to thirty-six hours; those who received a

8. Beddard: Clin. Jour., 1912-13, xl, 65. 
dram every four hours, in divided doses, acquired alkalinity in from forty-eight to sixty hours.

Irrespective of age, then, if soda is used, I believe that it is proper to make a solution in the ratio of $1: 20$. Of this solution half an ounce may be given every twenty minutes. No definite rule will fit every case, of course. One must often vary the dilution and the frequency of administration, but he should give the drug freely and in as concentrated a form as is well borne. Edsall's ${ }^{9}$ minimum dosage -100 grains of the bicarbonate - given as rapidly as possible, is much less than was used for many of our cases. The same may be said of Rachford's ${ }^{10}$ suggestion that 8 or 10 grains be given every two or three hours and of Koplik's small dosage. ${ }^{11}$

In fatal cases the progress of the disease was so rapid that it seemed impossible to give sufficient alkali - perhaps because "the alkalies are not of much value unless the supply of base to neutralize the acids has failed. If the cause is toxic . . . alkalies are unlikely to do good" $\left(\right.$ Cautley $\left.{ }^{12}\right)$.

Water proved the most satisfactory solvent for soda. Attempts to disguise the flavor of the salt with orange-juice or grape-juice were usually unnecessary. Of the two, orange-juice was preferable.

Sodium bicarbonate was given by rectum in thirty-two instances: half a dram of the salt in 2 ounces of water injected every hour or two. It was retained in eighteen. A saturated solution given by the drop method at the rate of a drop per second could be continued from twelve to twenty-four hours. It was useless to employ either method if a child had diarrhea.

Potassium citrate and sodium citrate were the alkalies of second choice, used both in conjunction with the bicarbonate and alone, either throughout the illness or during convalescence. One or the other citrate was given to fifty-two children. The citrates proved quite as palatable as the bicarbonate of sodium and were effective in procuring alkalinity. Some children could retain them who could not retain the bicarbonate; the reverse was occasionally true.

Citrates may be given to the amount of half a dram or a dram every hour, in a concentrated solution: 1 ounce of salt to 4 of water. So given, one procures an alkaline urine in less than twenty-four hours, and with these drugs alone one may conquer an acidosis with auto-

9. Edsall : Brit. Med. Jour., 1910, ii, 1033; Am. Jour. Med. Sc., 1903, cxxv, 629.

10. Rachford: Diseases of Children, New York, 1912, pp. 251 and 565.

11. Koplik: Diseases of Infancy and Childhood, New York, 1910, pp. 33 and 505.

12. Cautley: The Diseases of Infants and Children, London, 1910, 149. 
intoxication. The administration of any alkali should be continued for a few days after the subsidence of acute symptoms.

It was difficult to ward off an impending attack with any of these drugs. One child of 3 was given, as a preventive, 2 drams of the bicarbonate daily for four days before onset. Another child of 3 received for two days 4 drams of the bicarbonate daily, and for three days 3 drams of sodium citrate daily. So with three or four other cases.

In one fatal case dextrose (a 10 per cent. solution, 2 drams every three hours) was administered by rectum, but was not retained.

Once the vomiting had ceased, most of the children were placed on a simple diet low in fats. Beginning with such liquids as skimmed milk (with or without lime-water), rice-water, barley-water, oatmeal-water, orange-juice, grape-juice, we quickly added malted milk, cereals, crackers, toast, gruels and broths.

Lenhart ${ }^{13}$ believes that butter should be excluded, but not other fats. Koplik ${ }^{11}$ reduces milk to a minimum. Langstein and Meyer (see Morse ${ }^{\mathrm{I}}$ ) have stated that a fatty diet is dangerous for children when there is disturbance of carbohydrate metabolism. Morse, ${ }^{1}$ however, found that the variety of food seemed not to be a salient factor, although in some diseases, especially typhoid fever, in which the acetone bodies appear late, their presence was due to insufficient food or carbohydrates. To my mind, too great stress has been placed on providing a fat-free diet.

Other drugs we used symptomatically. Morphin was occasionally needed to control excitement. Saline solution was sometimes given by rectum. With sundry forms of medication that have been recommended I have had no experience. Let me enumerate a few :

1. Subcutaneous or intravenous injections of dextrose or levulose dissolved up to 10 per cent. strength in normal salt solution (Vander $\mathrm{Hoof}^{14}$ ).

2. Intravenous injection of salt solution $\left(\mathrm{Fisch}^{15}\right)$.

3. Administration of glucose by mouth. Chalfant ${ }^{16}$ says this is unsatisfactory. Mellanby ${ }^{17}$ advises the administration of glucose rather than the attempt to "neutralize a series of acids, already fully neutralized and of no more significance than creatin."

4. Stomach lavage $\left(\mathrm{Comby}^{18}\right)$.

13. Lenhart: Cleveland Med. Jour., 1911, x, 1017.

14. Vander Hoof: Charlotte Med. Jour., 1910, 1xii, 257.

15. Fischl: Pfaundler and Schlossmann's Diseases of Children, 1912, iii, 171.

16. Chalfant: Jour. Am. Med. Assn., 1912, lix, 852.

17. Mellanby: Lancet, London, 1911, ii, 8.

18. Comby: Arch. de méd. d. enf., 1909, xii, 721. 
5. Subcutaneous injection of sodium bicarbonate. Rachford ${ }^{10}$ advises 5 or 10 grains to the ounce. Experimentally, this has not proved serviceable $\left(\right.$ Rhamy ${ }^{19}$ ).

6. The administration of a mixture of sodium bicarbonate and lithium carbonate (Koplik ${ }^{11}$ ).

7. Venesection. Withdrawal of 500 c.c. of blood. Introduction of 500 c.c. normal saline solution with $10 \mathrm{gm}$. of sodium bicarbonate $\left(\right.$ Houda $\left.^{20}\right)$. This may cause thrombosis (Marchand ${ }^{21}$ ).

8. Administration of pancreatin ( Piper $^{6}$ in operative cases).

\section{REPORT OF CASE}

Let me give a brief history of a severe case, typical of what we saw in this epidemic:

Patient.-A well-developed, phlegmatic boy, 2 years old, had had duodenal indigestion several times, but recently had been active, vigorous and in good health. He had had no previous attacks of acidosis. His diet had been well regulated with low fats. One other child lived in the same house, but otherwise the boy had not been intimately associated with children. For three or four days he had had a coryza and mild bronchitis.

Sudden onset occurred with vomiting at $5 \mathrm{a}$. $\mathrm{m}$. The child continued to vomit at frequent intervals, especially if anything - even a little water - was taken by mouth. The vomitus became pale, watery and slightly yellow. With the aid of an enema he evacuated a semisolid brown stool-foul, slimy, acid. There was no diarrhea.

The temperature gradually rose to $103.5 \mathrm{~F}$; the pulse increased from 90 to 140. The boy's face was flushed with a contrasting whiteness about the mouth and nose. His breath came quickly, eagerly. One minute he was restless and uneasy, crying out for his mother, the next relapsing into stupor. In his waking moments he asked for water.

Examination. An examination made under difficulties showed coryza, a furred tongue, a retracted neck, pupils that were dilated but reacted to light, a slightly distended abdomen - nothing else. The urine was clear, strongly acid, with a specific gravity of 1.025 , free from albumin and sugar. Acetone and diacetic acid were present. The white count was elevated but not remarkable.

Treatment was difficult and without material effect. As the hours passed the symptoms became more intense, the child's abdomen was noticeably retracted, his eyes sunken, his body wasted. Finally, toward midnight he had a convulsion and in a few minutes was dead.

In this particular case the necropsy, twelve hours post mortem, gave the following data:

Pathologic Examination (Macroscopic).-Body of a well-developed, wellnourished, white male child. Pupils equal, dilated.

Primary incision shows skin thin, abdominal fat very slight; muscle firm, normal color, non-bleeding.

Peritoneal cavity: Very little fat in omentum. Superficial veins of intestines not remarkable. Intestinal mucosa normal except for conspicuous glands. Stomach mucosa injected.

19. Rhamy: Jour. Am. Med. Assn., 1912, 1viii, 628.

20. Houda: Jour. Am. Med. Assn., 1912, lviii, 1194.

21. Marchand: München. med. Wchnschr., 1912, lix, No. 4. 
Liver $10 \mathrm{~cm}$. below costal margin and $10 \mathrm{~cm}$. below xiphoid. Extends upward to cartilage of fifth rib. Prominent areas, size of a bean, white in color, on anterior surface. Gray in spots on section.

Adrenals, pancreas and kidneys normal.

Brain: Adhesion of dura to pia in region of closed posterior fontanelle. Vessels prominent and congested. Surface of brain moist but without excessive fluid.

Pathologic Examination (Microscopic).-- Liver: Fatty metamorphosis, edema, hemosiderin pigmentation.

Spleen: Acute hyperplasia.

Pancreas: Post-mortem degeneration.

Thymus: Atrophy. Necrosis and calcification of corpuscles of Hassal.

Stomach: Normal.

Appendix: Follicular hyperplasia.

Diagnosis: Fatty degeneration of the liver; congestion of the brain.

Cultures from the several organs were negative except one from the base of the brain. Here we cultivated two kinds of cocci. One was unusually large and occurred in pairs; its colonies were white. The other coccus was as large as staphylococcus; its colonies were translucent.

Antigen was made from the mixture, and from the larger coccus and from a culture of meningococcus. All of these gave a negative test with blood-serum from a second case of acidosis with atto-intoxication. We cannot rule out the possibility that the immune bodies which fix the complement had not yet developed in this serum.

By blood-culture we obtained from this latter case a coccus which was not identical with either of the cultures procured at autopsy. Numerous cultures made from throats and nasal discharges in other cases gave variegated growths from which no specific organism could be isolated.

\section{GENERAL DISCUSSION}

Acidosis has been defined as an "abnormal metabolism of carbon leading to the appearance of organic acids in the blood and urine, and the formation of ammonia to neutralize these acids" (Cautley ${ }^{12}$ ).

These organic acids, beta-oxybutyric and diacetic, with acetone, comprise the acetone bodies. It is said that oxybutyric acid is the precursor of diacetic acid and acetone the final product of the series; yet there is no good reason for so believing, except the order of their appearance in the urine, the similarity of their chemical formulas and the fact that diacetic acid, when heated, changes to acetone. Against this view is the fact that acetone can readily be formed from a number of other substances. Furthermore, the administration of sodium acetoacetate is followed by the elimination of beta-oxybutyric, just the reverse of the common understanding of their order of formation $\left(\right.$ Rhamy $\left.^{19}\right)$.

When the total amount of acetone bodies formed is low, the percentage of acetone itself is high; when the total amount of acetone bodies is high, the percentage of acetone itself is low (Piper, ${ }^{6}$ in postoperative cases). If the excretion of acetone exceeds $0.5 \mathrm{gm}$. daily diacetic acid is present also. If the excretion of acetone exceeds $1 \mathrm{gm}$. daily, beta-oxybutyric acid is present $\left(\operatorname{Beddard}^{8}\right)$. 
Koplik $^{11}$ has stated that acetone arises from the splitting of nitrogenous substances of the body. Von Noorden, ${ }^{22}$ however, says that though tissue destruction is a necessary factor, there is no evidence that acetone comes from the breaking down of proteids. It is readily obtained from fats and has been obtained from carbohydrates (Bracket $\mathrm{t}^{23}$ ). Knoop ${ }^{24}$ has demonstrated the formation of acetone bodies from fatty acids. By feeding $100 \mathrm{gm}$ : of oleic acid to a healthy man, Joslin (see Brackett, Stone and Low $^{23}$ ) caused an excretion of over $1,700 \mathrm{gm}$. of acetone in twenty-four hours, without producing other symptoms. Geelmuyden noticed acetonuria after adding olive oil and butter to a normal diet $\left(\right.$ Rhamy $\left.{ }^{19}\right)$.

The processes by which fat is burned are dependent on the simultaneous combustion of carbohydrates. The acetone bodies are probably excreted as a result of a lessened oxidation of fat, brought about either indirectly as a result of lessened sugar combustion, or by a direct influence of some unknown nature on fat combustion (Howland and Richards ${ }^{4}$ ). This direct influence, according to Guthrie, ${ }^{25}$ is an intoxication produced by absorption of toxins from the intestines, by bacterial poisons - for example, pneumonia - or by inorganic poisons - for example, phosphorus. The liver, already laden with fat, becomes surcharged with more fat derived from the subcutaneous tissues. Should the overtaxed liver fail to metabolize the enormous quantity of fat thus brought to it, the circulation becomes flooded with the products of imperfect oxidation.

Brackett ${ }^{23}$ states that although the presence of primary intestinal toxins has not been shown, it is probable that they exist, while Mellanby ${ }^{17}$ suggests that such toxins arise directly at the portal area from intestinal infection or putrefaction.

The acetone bodies constantly appear in some lesions of the pancreas, which fact, too, is in accord with the intestinal origin of some cases of acid intoxication, since disturbance of pancreatic function would reduce digestive activity in the duodenum with resulting faulty cleavage of fats $\left(\right.$ Rhamy $\left.{ }^{19}\right)$.

We know that acetone is found in very small amounts in the urine of healthy children (Baginsky ${ }^{26}$ ), never exceeding $1 \mathrm{cg}$. in twenty-four hours (Langstein and Meyer). Indeed, acetone and its associates, diacetic and oxybutyric acids, are possibly being constantly formed in minute quantities in normal metabolism ( Rhamy ${ }^{19}$ ).

22. Von Noorden: Clinical Treatises on Metabolism. New York, 1903.

23. Brackett, Stone and Low: Boston Med. and Surg. Jour., 1904, cli, 2.

24. Knoop:Ztschr. f. d. gesammte Biochemie, 1905, vi, 150.

25. Guthrie: Brit. Med. Jour., 1908, ii, 1158.

26. Baginsky: Arch. f. Kinderh., 1888, ix, 1. 
In increasing amounts they are formed in many pathologic conditions : in starvation and cachexia ; in eclampsia ; in poisoning by phosphorus, salicylates and by other drugs; in hepatic lesions like acute yellow atrophy; in diabetes; in nervous disturbances due to fright; in the so-called delayed anesthetic poisoning. Sedgwick ${ }^{27}$ and Smith ${ }^{28}$ have called attention to the frequency with which their formation accompanies adenoids. Comby ${ }^{18}$ remarks that 50 per cent. of his series had appendicitis and believes that this is an etiologic factor that has been overlooked by other observers. Harris ${ }^{29}$ notes their occurrence in scarlet fever. Gordon ${ }^{\text {s0 }}$ (quoting Reiche) states that acetonuria was present in 60 per cent. of a series of thirty-two hundred diphtheria cases. Frew ${ }^{31}$ examined 662 out-patient children of whom 61.6 per cent. showed acetonuria. These were largely infectious cases and the nature of the concomitant infection seemed not to affect this ratio; except that in typhoid fever only 15.6 per cent. of the children showed acetonuria. Chalfant ${ }^{16}$ obtained positive results in 86.45 per cent. of his cases, affected with postoperative vomiting.

Morse ${ }^{1}$ states that acetone bodies are present in the urine of infants and children under approximately the same conditions as in adults. They are often present in acute diseases accompanied by high fever (especially in the acute exanthems, diphtheria and pneumonia), vary, as a rule, directly with the height of the fever and disappear with the fall of the temperature. Morse has noted, also, the enormous increase of these bodies in children during convulsions, but thinks they are not the cause of the convulsions. Acetone bodies are rarely found in the urine in gastro-intestinal disorders of infancy but are commonly found during childhood, whether the disorders are acute or chronic. There may be no accompanying symptoms of acid intoxication.

In these instances, although a state of acidosis exists, with the acetone bodies present in the blood, the hydrogen ions are "rapidly neutralized by sodium in the tissue fluids, potassium in the cells, and by alkaline earths chiefly derived from bones. If this is not enough, the excess is neutralized by ammonia, derived from protein, which would normally have been metabolized into urea" (Cautley ${ }^{12}$ ). There is a consequent increase in the excretion of ammonia and a diminution in urea (Rhamy ${ }^{19}$ ). In children it is invariably true that acidosis in the body is accompanied by an increase in the excretion of ammonia (Langstein and Meyer).

27. Sedgwick: Am. Jour. Dis. Child., 1912, iii, 209.

28. Smith: Lancet, London, 1911, ii, 1186.

29. Harris: Lancet, London, 1910, $\mathrm{i}, 1346$.

30. Gordon: New York Med. Jour., 1913, xcvii, 529.

31. Frew: Lancet, London, 1911, ii, 1264. 
"Should more acid be produced than can be thus neutralized, the reaction of the tissue fluids may be altered and cause symptoms of acid intoxication. It is therefore evident that acidosis may be very common, though acid intoxication is rare. It can exist long before the tissue fluids are rendered less alkaline and before toxic symptoms arise. One passes gradually into the other (Cautley ${ }^{12}$ )."

It is said that acetone is non-toxic; it is argued that in "recurrent vomiting" acidosis can be prevented by the administration of dextrose and yet the acute symptoms occur just the same (Beddard $\left.{ }^{8}\right) . \quad$ Edsall $^{9}$ has said that acetone and diacetic acid have little if any significance in producing symptoms, for neither is very toxic; that beta-oxybutyric acid, however, is more important and produces the only form of autointoxication. According to Piper, ${ }^{6}$ the acetone bodies, when excreted freely, are harmless. Injected intraperitoneally and subcutaneously into guinea-pigs, large amounts of acetone gave no anatomic lesions unless the administration was prolonged for many days (Brackett ${ }^{23}$ ).

Despite the fact that the acetone bodies are only mildly toxic, the general conception is that oxybutyric and diacetic acids, by uniting with the fixed alkalies, reduce the alkalinity of the tissues and thereby produce a condition of toxemia. The amounts of these two acids are in constant relation and with acetone vary directly as the severity of the intoxication $\left(\mathrm{Edsall}^{9}\right)$. The ammonia excretion is perhaps another index of the degree of intoxication, although Ewing ${ }^{32}$ found that in pregnancy the estimation of ammonia nitrogen did not follow this rule.

With the neutralization of the alkalies of the tissues, the blood can carry less carbon dioxid; there may be a decrease from the normal 24 per cent. to 3 per cent. Hence, carbon dioxid accumulates in the tissues until we have a condition of internal suffocation (Vander Hoof $^{14}$ ).

At variance with this theory is Lenhart's ${ }^{13}$ view that while the blood is less alkaline to titration, this fact does not prevent it from carrying carbon dioxicl. Venous blood will take up carbon dioxid and in acid intoxication the carbon dioxid of the tissues is not excessive. The carbon dioxid is an incident. Benedict, ${ }^{33}$ too, while admitting that the alkalinity of the tissues cannot be inferred from that of the blood, has stated that in conditions other than diabetes the alkalinity of the blood may be lower than that ever observed in diabetic coma, without the appearance of the symptoms of intoxication.

Rachford ${ }^{10}$ has suggested that the acids, besides removing alkaline bases which are needed in metabolism, have a direct toxic action in that they bring poisonous alkaline bases (as ammonia) into the blood. Ewing, ${ }^{32}$ too, from his experimental work, has concluded that the intoxication may be due to the accumulating antecedents of urea. $\mathrm{He}$

32. Ewing: Arch. Int. Med., 1908, ii, 330.

33. Benedict: Arch. f. d. ges. Physiol., 1906, cxv, 106. 
adds that none of the principles of the theory of acid intoxication have been proved - namely, carbon dioxid asphyxiation, degeneration of the vital organs by withdrawal of alkalies and reduced alkalinity.

Partial reports of a dozen or more necropsies in children are available. In these the predominating lesion was enlargement and fatty infiltration of the liver. Other data were:

LANGMEad, ${ }^{34}$ CASE 1.-Kidneys fatty. No nephritis. Mucous membrane of posterior wall of stomach mottled by dark red areas of hemorrhage.

LANGMEAD, CASE 2.-No organism could be grown from the blood, spleen or bile. Nine c.c. of blood yielded 0.33 per cent. acetone.

LANGMEAD, CASE 3.-Three c.c. of blood yielded 0.24 per cent. acetone.

Griffith. ${ }^{2}-$ Necrotic changes in mucous membrane of stomach and intestine; slight parenchymatous alterations in pancreas, spleen and kidneys.

BracketT $^{* 3}$ (Four Necropsies). - Only marked lesion was extreme fatty degeneration of liver and muscles.

Aвт. ${ }^{35}$ - Fatty degeneration of all the organs.

Rhamy ${ }^{19}$ believes it is probable that there are essential changes in the blood-vessels, brain and excretory organs, ending in acute degeneration of the liver. Crile's ${ }^{36}$ experiments would lead one to anticipate, also, changes in the adrenals.

Rosenfeld (see Langmead ${ }^{34}$ ) showed that if animals were fattened on mutton-fat and then poisoned with phloridzin, acute fatty infiltration of the liver occurred and that the fat so deposited was mutton-fat. From this Langmead concludes that the liver condition is a result, not a cause. Brackett ${ }^{23}$ thinks the adipose tissue of the body furnishes the fat in the liver.

There is evidence, then, that the acetone bodies are derived from fatty acids imperfectly metabolized in the liver; that this imperfect metabolism may be coincident with lessened sugar combustion; but that there is an immediate exciting cause for this imperfect metabolism.

Sometimes an intestinal disturbance is the only obvious exciting cause, and here we have the "digestive" type of acidosis. Again, we have primary poisoning from an inorganic poison, while in a third group one must consider a concomitant infection. In the "infectious" type, however, there may be intestinal disturbance, evidenced by diarrhea, foul stools and the like. The increased excretion of ammonia may be due not only to the incomplete metabolism of urea, but to the entrance through the portal circulation of a bacteriologic product accruing from putrefaction in the large intestine (Folin and Denis ${ }^{37}$ ).

34. Langmead: Brit. Med. Jour., 1907, ii, 819; 1905, i, 350.

35. Abt: Am. Jour. Med. Sc., 1914, cxlvii, 86; Jour. Am. Med. Assn., 1910, lv, 991 (discussion).

36. Crile: Personal communication.

37. Folin and Denis: Jour. Biol. Chem., 1912, xi, 161. 
In the Concord epidemic one saw acidosis with auto-intoxication in all degrees of severity; one saw both initial and recurrent cases. I believe that "acid auto-intoxication," "recurrent vomiting" and "cyclic vomiting" are merely degrees of an acidosis. The beneficial effects of alkaline treatment suggest that the symptoms are due to an excess of acid. In spite of the fact that the acetone bodies formed are apparently less in amount than those found in diabetes, their constant presence suggests, further, as Morse ${ }^{1}$ has said, that they have an intimate relation with the symptoms; that they comprise, in fact, the acids causing this hyperacidity.

The Concord epidemic bore an analogy to the Birmingham epidemic reported by Parke. ${ }^{38}$ It differed in that the Birmingham cases had an initial diarrhea, constant enlargement of the liver, absence of cyanosis and not infrequently absence of vomiting. Parke reported eighteen cases in infants under 20 months with an alarming death-rate ( 71 per cent.). It is also of interest that the symptoms in our epidemic were not unlike those attributed in several localities last year to the consumption of blighted chestnuts.

To the best of my knowledge an extensive epidemic similar to that in Concord has not heretofore been reported. With so few bacteriologic data I can offer slight evidence that any organism was the immediate exciting cause. Nevertheless, I believe that the prevailing respiratory infection was significant; that this infection was usually conveyed by direct contact; that it was selective and that some infected children did not develop acidosis.

My thanks are due to the several physicians whose cases are included in this compilation and to various officials at the Harvard Medical School who examined the bacteriologic and pathologic specimens.

38. Parke: Jour. Am. Med. Assn., 1910, 1v, 991; 1907, xlix, 1827. 